The nature of changes in the structure of the tissue-equivalent phantom PAG-3 in the focus zone indicates the role of acoustic cavitation and mechanical shock-wave shifts that form a thermal pattern. The latter is characterized by the following phenomena: accumulation of thermal energy, limited heat propagation, which determines the therapeutic effectiveness of HIFU exposure, however, it is advisable to take into account the role of mechanical effects in focused ultrasound therapy.

Thus, the obtained data allow us to suggest the role of shock-wave shifts in the tissueequivalent phantoms under HIFU exposure, which are involved in the formation of the thermal pattern and in the distribution of temperature regimes in the perifocal zones.

$$
* * *
$$

1. Brown M.R.D., Farquhar-Smith P., Williams J.E. , ter Haar G., de Souza N.M. The Use of High-Intensity Focused Ultrasound as a Novel Treatment for Painful Conditions-A Description and Narrative Review of the Literature// Br. J. Anaesth. - 2015.- Vol.115, N4.- P.520-530. doi: 10.1093/bja/aev302.

2. Bing Ch. , Cheng B., Staruch RM, Nofiele J., Staruch MW, Szczepanski D., Farrow-Gillespie A., Yang A., Laetsch TW, Chopra R. Breath-hold MR-HIFU Hyperthermia: Phantom and in vivo Feasibility// Int. J. Hyperthermia.- . 2019.- Vol.36, N1.-P.1084-1097. doi: 10.1080/02656736.2019.1679893.

3. Maruvada S., Liu Y., Pritchard W.F., Herman B.A., Harris G.R. Comparative study of temperature measurements in ex vivo swine muscle and a tissue-mimicking material during high intensity focused ultrasound exposures// Phys. Med. Biol. - 2012, No. 57.- P. 1-19. doi:10.1088/0031-9155/57/1/1

4. Gryzunov V.V., Osipov A.S. Fundamentals of Cellular Pathophysiology. - SPb, Polytech-Press, 2020. 239 p.

5. Kawano S., Kojima M., Higuchi Y., Sugimoto M., Ikeda K., Sakuyama N., Takahashi S., Hayashi R., Ochiai A., Saito N. Assessment of elasticity of colorectal cancer tissue, clinical utility, pathological and phenotypical relevance// Cancer Sci. - 2015.- Vol. 106.-P. 1232-1239. doi: 10.1111/cas.12720

\title{
Moskalets O.V. \\ The incidence of anti-rituximab antibodies in patients with lymphoproliferation
}

Moscow Regional Research Clinical Institute named after M.F.Vladimirskij

(Russia, Moscow)

doi 10.18411/gq-31-03-2021-09

idsp sciencerussia-31-03-2021-09

\section{Introduction.}

Monoclonal antibodies have become mandatory for neoplastic targeted therapies as well as chronic inflammatory and autoimmune diseases. Rituximab is a chimeric monoclonal antibody directed against CD20 antigen that is expressed on normal and malignant human B cells [1,2]. It was the first monoclonal antibody to be approved for therapeutic use [2]. Treatment with rituximab at standard weekly dosing is effective in more than $50 \%$ of patients with relapsed or refractory CD20-positive follicular non-Hodgkin's lymphoma, but is not curative. It is less effective in other subtypes of CD20-positive lymphoma and for retreatment, even with CD20 still expressed [3]. Thus, binding of rituximab to CD20 is not sufficient to kill many lymphoma cells, indicating that there are mechanisms of resistance.

Many observations show that antibodies to rituximab are generated in some patients during rituximab treatment and may be associated with a less favourable response to treatment. [4-7]. However, antibodies that bind a drug are sometimes found in pre-treatment serum samples, with the amount depending on drug, assay, and patient population. The accurate prediction and assessment of (clinically relevant) immunogenicity remains a challenging endeavor [4].

Purpose of the study - to determine the incidence of anti-rituximab antibodies (ARA) in patients with non-Hodgkin's lymphoma (nHL) treated by rituximab.

\section{Materials and methods.}

The study involved 32 patients with nHL (11 newly diagnosed, 21 - resistant / recurrent form), aged from 36 to 70 years (average age 49,5 years), of witch 18 women and 14 men and and 13 practically healthy individuals, matched by age and sex. 
In $55 \%$ of patients, stage 2 of the disease was detected, in $45 \%$ of patients - stages 3 and 4. Patients with refractory / relapsing forms have previously received 4-6 courses of R-FC therapy. Determination of anti-rituximab antibodies in peripheral blood serum was performed by enzyme-linked immunoassay using a test system manufactured by Bender Medsystems (Austria) (semi-quantitative analysis).

\section{Results.}

None of the patients with newly diagnosed disease have ARA. Positive results were recorded in 7 (33\%) patients who received rituximab earlier. Of particular note is a patient with a very high antibody level (74,7 c.u.) who received 6 courses of combination therapy and showed pronounced progression of the disease. At the same, in the group of practically healthy persons, positive results were obtained in $2(15,4 \%)$ cases, in particuilar, with a procedural nurse who regularly contacts the drug.

\section{Conclusion.}

ARA have been found in patients with lymphoproliferation and other diagnoses but the data on clinical implications of the development of these antibodies are limited. The data obtained in this study demonstrated that they are revealed in $33 \%$ of patients with resistant forms of the disease treated by rituximab. Besides, pre-existing anti-rituximab antibodies were detected in several serum samples in control group. Of course, it should be borne in mind that the effect of ARA on the therapeutic efficacy of the drug can be different: it could be targeting predominantly the idiotype and thus clinically relevant, or due to pre-dose antibodies that can bind the therapeutic antibody, but are often irrelevant. If we suppose that immunogenicity is an important factor that should be considered in the overall treatment strategy, we should take actions to reduce antidrug antibodies formation: modifying drug administration; increasing dose; decreasing immunogenicity by adding immunosuppressive agents to the regimen or using new drugs which are supposed to be less immunogenic such as humanized or fully human monoclonal antibodies.

$$
* * *
$$

1. Chan A.C., Carter R.T. Therapeutic antibodies for autoimmunity and inflammation. Nat. Rev. Immunol. 2009. Vol.10. P.301-316. Doi:10.1038/nri2761.

2. Einarsson J.T., Evert M., Geborek P., Saxne T., Lundgren M., Kapetanovic M.C. Rituximab in clinical practice: dosage, drug adherence, Ig levels, infections, and drug antibodies. Clin. Rheumatol. 2017 Vol.36(2). P.2743-2750. Doi 10.1007/s10067-017-3848-6.

3. Maloney D.R. Anti-CD20 antibody therapy for B-cell lymphomas. N Engl. J. Med. 2012.Vol.316. P.2008-2018 DoI:10/1056/NEJMct1114348.

4. Rosenberg A.S., Sauna Z.E.Immunogenecity assesment during the development of protein therapeutics. J. Pharm. Pharmacol. 2018. Vol.70(5). P.584-594. Doi:10.1111/jphp12810.

5. Krishna M., Nadler S.G. Immunogenecity to biotherapeutics - the role of anti-drug immune complexes. Front. Immunol. 2016; 7:21 Doi: 10.3389/fimmu.2016.00021.

6. Tada M., Ishii-Watabe A., Suzuki T., Kawasaki N. Development and characterisationof an anti-rituximab monoclonal antibodies. Mabs. 201 8. Vol.10(3). P.370-379. Doi: 10.1080/19420862.2018.1424610.

7. vanSchi K.A., Wolbink G.J., Respens T. Cross-reactive and pre-existing antibodies to therapeutic antibodies - Effects on treatmentand immunogenecity. Mabs. 2015. Vol.7. 662-671. DoI: $10.1080 / 19420862.2015 .10481111$. 